\title{
Neuroblastoma specific effects of DR-nm23 and its mutant forms on differentiation and apoptosis
}

\author{
A Negroni ${ }^{1}$, D Venturelli ${ }^{2}$, B Tanno ${ }^{1}, \mathrm{R}$ Amendola ${ }^{1}$, \\ S Ransac ${ }^{3}$, V Cesi $^{1}$, B Calabretta ${ }^{2}$ and G Raschella ${ }^{\star, 1}$ \\ 1 Section of Toxicology and Biomedical Sciences, Ente Nuove Tecnologie e \\ Ambiente (ENEA) Via Anguillarese 301, 00060 Rome, Italy \\ 2 Kimmel Cancer Institute, Thomas Jefferson University, B.L.S.B., 233 S. 10th \\ St., Philadelphia, PA 19107, USA \\ 3 Institut de Biochimie et Genetique Cellulaires, 33077 Bordeaux, France \\ * Corresponding author: Giuseppe Raschellà, Section of Toxicology and \\ Biomedical Sciences, Ente Nuove Tecnologie e Ambiente (ENEA) Via \\ Anguillarese 301, 00060 Rome, Italy. Tel: +39 (06) 3048.3172 \\ Fax: +39 (06) 3048.6559; E-mail: raschella@casaccia.enea.it
}

Received 13.10.99; revised 21.4.00; accepted 11.5.00

Edited by CJ Thiele

\begin{abstract}
DR-nm23 belongs to a gene family which includes nm23-H1, originally identified as a candidate metastasis suppressor gene. Nm23 genes are expressed in different tumor types where their levels have been alternatively associated with reduced or increased metastatic potential. Nm23-H1, -H2, DR$\mathrm{nm} 23$ and $\mathrm{nm} 23-\mathrm{H} 4$ all possess NDP kinase activity. Overexpression of DR-nm23 inhibits differentiation and promotes apoptosis in hematopoietic cells. By contrast, it induces morphological and biochemical changes associated with neural differentiation in neuroblastoma cells. In this study, we show that mutations in the catalytic domain and in the serine 61 phosphorylation site, possibly required for protein-protein interactions, impair the ability of DR-nm23 to induce neural differentiation. Moreover, neuroblastoma cells overexpressing wild-type or mutant DR-nm23 are less sensitive to apoptosis triggered by serum withdrawal. By subcellular fractionation, wild-type and mutant DR-nm23 localize in the cytoplasm and prevalently in the mitochondrial fraction. In coimmunoprecipitation experiments, wild-type DR-nm23 binds other members of nm23 family, but mutations in the catalytic and in the RGD domains and in serine 61 inhibit the formation of hetero-multimers. Thus, the integrity of the NDP kinase activity and the presence of a serine residue in position 61 seem essential for the ability of DR-nm23 to trigger differentiation and to bind other Nm23 proteins, but not for the anti-apoptotic effect in neuroblastoma cells. These studies underline the tissue specificity of the biological effects induced by DR-nm23 expression. Cell Death and Differentiation (2000) 7, 843-850.
\end{abstract}

Keywords: DR-nm23; neuroblastoma; differentiation; apoptosis

Abbreviations: NB, neuroblastoma; SDS - PAGE, polyacrylamide gel electrophoresis in presence of sodium dodecyl sulphate; PVDF, polyvinyldifluorene

\section{Introduction}

The nm23 gene family includes a growing number of genes. The most characterized members of the family, $\mathrm{nm} 23-\mathrm{H} 1$ and $-\mathrm{H} 2$, are expressed in several types of tumors ${ }^{1}$ in some of these, the $\mathrm{nm} 23-\mathrm{H} 1$ gene has been associated with reduced metastatic potential. ${ }^{2,3}$ DR-nm23 is involved in differentiation and apoptotic process in myeloid and neuroblastoma cells. ${ }^{4,5}$ Other members of the family have recently been isolated: $\mathrm{nm} 23-\mathrm{H} 4^{6}$ that is localized in the mitochondria, $\mathrm{nm} 23-\mathrm{H} 5^{7}$ that is specifically involved in early stages of spermatogenesis and the murine $\mathrm{nm} 23-\mathrm{M} 2$ that is widely expressed in the central nervous system. ${ }^{8}$

Despite their relatively small size, several properties have been attributed to $\mathrm{nm} 23-\mathrm{H} 1$ proteins. Although expressed in different cell types and in variable amounts, at least nm23-H1, nm23-H2, DR-nm23 and nm23-H4 possess a common nucleoside diphosphate kinase (NDPK) activity. ${ }^{9}$ NDP kinases play important regulatory roles in normal development ${ }^{10}$ proliferation $^{11}$ and differentiation. ${ }^{12}$ Nevertheless, this enzymatic activity does not seem to be the only feature responsible for the observed metastasis suppression function of $\mathrm{nm} 23-\mathrm{H} 1$, since phosphorylation at certain serine amino acid residues has been reported to correlate with this activity. ${ }^{13} \mathrm{~A}$ distinct function as a transcription factor for c-myc via binding to polypyrimidine sequences has been reported for $\mathrm{nm} 23-\mathrm{H} 2$ but not for nm23-H1. ${ }^{14,15}$ Recently, an unusual serine/ threonine-specific protein phosphotransferase activity has been attributed in vitro to a complex formed by $\mathrm{nm} 23-\mathrm{H} 1$ and glyceraldehyde-3-phosphate dehydrogenase (GAPDH) enzymes. This novel nm23 might be relevant for many if not all signal transduction events leading to carcinogenesis and metastasis, ${ }^{16}$ although the occurrence of the phosphotransferase activity mediated by the nm23H1/GAPDH complex awaits a demonstration in vivo.

In a previous study, ${ }^{5}$ we have shown that ectopic expression of DR-nm23 induces neuroblastoma cells to undergo neuronal and schwannocitic differentiation, perhaps by altering the adhesion properties of neuroblastoma cells through the regulation of integrins expression. ${ }^{5}$

DR-nm23 protein, like other members of the family, has structural characteristics that suggest multiple roles. It shares approximately $65 \%$ of homology with proteins encoded by other members of the family, including domains and amino acid residues postulated to be important for nm23 functions, such as a RGD domain that, in other proteins, functions as an integrin binding domain, and a histidine residue which is necessary for the NDP kinase activity. In addition, sequence analysis of DRnm23 protein revealed a leucine zipper-like domain which spans from aminoacid $60-84 .^{4}$

In this study, we investigated the effects of mutations in the catalytic and RGD domains, and in the serine 61 
phosphorylation site of DR-nm23 on the ability of this protein to affect differentiation and/or apoptosis of neuroblastoma cells. Furthermore, we examined the relevance of these mutations in modulating the ability of DR-nm23 to form hetero-multimers with other members of the same gene family.

\section{Results}

\section{Effects of DR-nm23 mutations on neural differentiation and apoptosis of neuroblastoma cells}

We generated three different mutants of the human DR-nm23 cDNA at sites likely to affect the biological function of the protein. The first mutant contained a deletion of the RGD motif (LXSP-HA $\Delta$ RGD DR-nm23-mutant described as RGD-mutant) which might be involved in substrate binding. The second mutant was generated by substituting histidine 134, corresponding to the histidine 118 in $\mathrm{nm} 23-\mathrm{H} 1,{ }^{9}$ in the catalytic domain with a glutamine (LXSP-HA H134Q DR-nm23 described as mutant $\mathrm{H}-\mathrm{Q}$ ) and the third mutant was obtained by substitution of a serine at position 61 , corresponding to the serine 44 in $\mathrm{nm} 23-\mathrm{H} 1,{ }^{13}$ with a proline. (LXSP-HA S61P DRnm23 described as mutant S-P). The three mutants were cloned in the retroviral expression vector LXSP in frame with the influenza-hemoagglutinin $(\mathrm{HA})$ tag. The WT, $\mathrm{H}-\mathrm{Q}$ and S-P DR-nm23 forms were also cloned in prokaryotic expression vector $\mathrm{pQE}-60$ and proteins were produced. In a biochemical assay, NDP kinase activity was $3 \mathrm{U} / \mathrm{ml}$ for WT, $0 \mathrm{U} / \mathrm{ml}$ for $\mathrm{H}-\mathrm{Q}$ mutant and $2.6 \mathrm{U} / \mathrm{ml}$ for S-P mutant at a protein concentration of $0.15,0.31$ and $0.1 \mathrm{mg} / \mathrm{ml}$ respectively.

The murine neuroblastoma cell line N1E115, which is able to differentiate to neuronal cells by treatment with retinoic acid or dimethyl sulphoxide (DMSO), ${ }^{18}$ was transfected with each mutant or with wild-type DR-nm23 used as control. After transfection and puromycin selection, pools of wild-type- and mutant-transfected cells were collected to minimize the consequences of clonal variability and to mimic the heterogeneity of the parental cell line. All transfectants were tested for ectopic expression of DRnm23 protein by Western blot using an antibody specific for the HA epitope. Comparable levels of HA-DR-nm23 were detected in wild-type- and mutant-transfected cells (Figure 1C). Thus, the mutations introduced in DR-nm23 coding sequence do not seem to influence the levels of the protein.

Cell morphology was then evaluated: an increase of neurite extension was observed in wild-type- (Figure 1A,b) and RGD- (Figure 1A,c) transfectants as compared to the parental line transfected with the empty vector (Figure $1 \mathrm{~A}, \mathrm{a}$ ) and the S-P (Figure 1A,d) and $\mathrm{H}-\mathrm{Q}$ (Figure 1A,e) mutants which showed a blastoid morphology. These morphological observations were supported by $\beta$-galactosidase assay, in which N1E 115 cell line was co-transfected with the wild-type or mutant DR-nm23 expression plasmids, together with a $\beta$-galactosidase plasmid. Blue cells ( $\beta$-gal positives) were counted and morphologically evaluated for neurite extension by two investigators in three different experiments. Only the RGD-mutant and the wild-type gene induced morphological modifications consistent with differ- entiation. In fact, $34 \%( \pm 4.2)$ of the cells transfected with wild type DR-nm23 and $35 \%( \pm 1.4)$ of those transfected with RGD- DR-nm23 were scored as differentiated compared with $18 \%( \pm 2.1)$ and $16 \%( \pm 1.4)$ for the $\mathrm{H}-\mathrm{Q}$ and the S-P mutants, respectively (Figure 1B).

To correlate morphology with changes in gene expression indicative of maturation, we monitored the expression of $\mathrm{N}$-myc, a proto-oncogene whose expression is downregulated in the early phases of neuroblastoma differentiation. ${ }^{19}$ By Western blot, $\mathrm{N}$-myc expression decreased in wild type- and RGD-mutant transfectants compared to the other two mutants, S-P and $\mathrm{H}-\mathrm{Q}$, that showed $\mathrm{N}$-myc expression levels comparable to those of the parental line transfected with the empty vector (Figure 1C). Compared to the control, densitometric analysis of the blot indicated a 3.4 and 2.0-fold decrease of N-myc expression in the WT and in the RGD-mutant, respectively (Figure 1D).

DR-nm23 is up-regulated in the early stages of myeloid differentiation, and its constitutive expression in $32 \mathrm{Dcl} 3$ myeloid precursor cells results in inhibition of granulocyte differentiation induced by granulocyte colony-stimulating factor (G-CSF) and causes apoptotic cell death. ${ }^{4}$ To test if ectopic expression of wild-type and mutant DR-nm23 triggers neuroectodermal cells towards an apoptotic pathway, cell transfectants were grown in medium supplemented with $0.1 \%$ fetal bovine serum (instead of $7.5 \%$ ). After 24 and $48 \mathrm{~h}$, the parental cell line transfected with the empty vector, and the wild-type- and RGD-mutant transfectants showed a typical differentiated morphology, while the other two mutants maintained a prevalent blastoid phenotype with round, enlarged cell bodies and few cells outgrowing short neurites (Figure 2A,a-e). By indirect immunofluorescence, wild-type and the RGD-mutant transfectants showed a marked increase in the expression of the differentiation marker NF $160 \mathrm{kDa}$, whereas cells transfected with the S-P and the $\mathrm{H}-\mathrm{Q}$ mutants were almost completely negative (Figure 2B,a-e). Apoptotic cells after $48 \mathrm{~h}$ of culture in $0.1 \%$ fetal bovine serum were scored by TUNEL assay which detects the presence of DNA breaks characteristic of apoptosis and preceding nuclear fragmentation. In reduced serum conditions the frequency of apoptotic cells increased in all cell lines tested. However, the cell lines transfected with wild-type, $\mathrm{H}-\mathrm{Q}, \mathrm{S}-\mathrm{P}$ and RGD-mutants showed 7.0 $( \pm 0.7), 5.4( \pm 0.8), 2.2( \pm 0.3)$, and $3.6 \%( \pm 0.3)$ of apoptotic cells respectively as compared to $10 \%$ in cells transfected with the empty vector (Figure 3). In four independent assays, the difference in the percentage of apoptotic cells between each DR-nm23 transfectant and cells transfected with the empty vector was statistically significant $(P \leqslant 0.05)$ using a one-tailed $t$-Student's test. Thus, unlike $32 \mathrm{Dcl} 3$ cells, ${ }^{4}$ DR-nm23 expression seems to protect neuroblastoma cells from serum deprivationinduced apoptosis. The anti-apoptotic effect of DR-nm23 is not impaired by the mutations tested in this study.

\section{Subcellular localization of DR-nm23 protein}

To assess whether the differences in differentiation and apoptosis in cells transfected with wild-type or mutant DRnm23 gene reflected a distinct localization of the encoded 
A
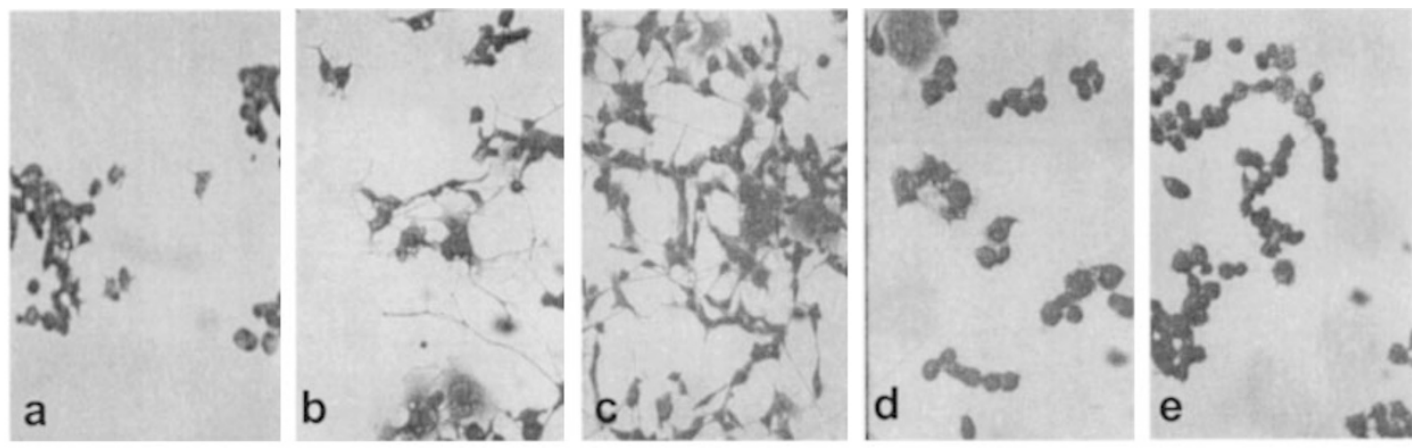

B

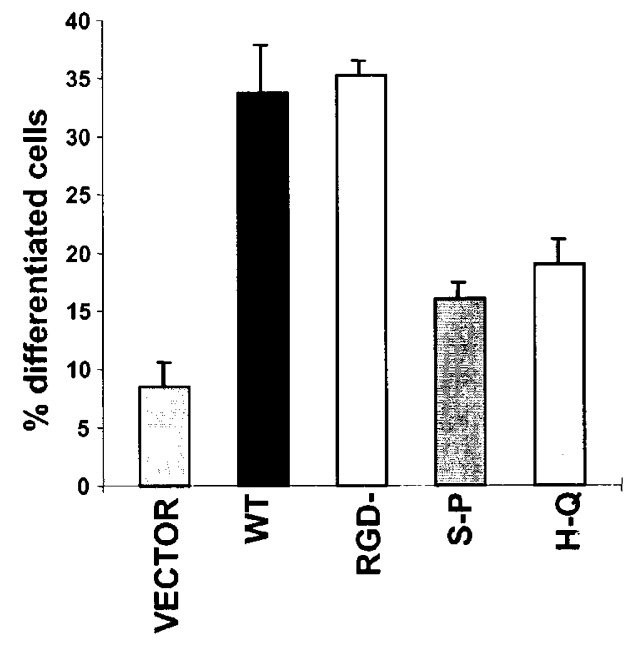

C

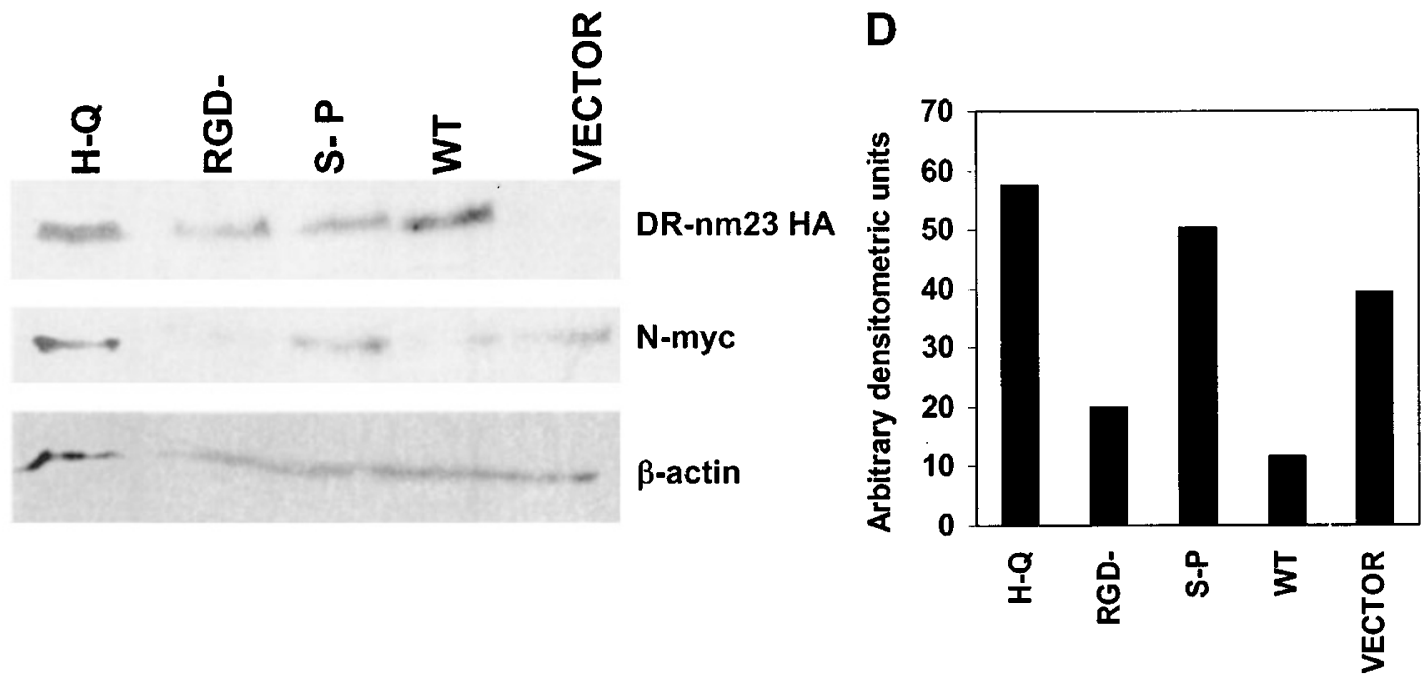

Figure 1 Effects of Dr-nm23 mutations on neuroblastoma differentiation. (A) Cell morphology of N1E 115 cells transfected with the empty vector (a), with wildtype DR-nm23 (b), with the RGD-, (c) the S-P (d) or the H-Q (e) mutant. Neurites outgrowth was detected only in the wild-type and RGD-transfectants. (B) Percentage of differentiated cells scored after staining for $\beta$-galactosidase activity N1E 115 cells co-transfected with a $\beta$-gal vector and wild-type or mutant DR$\mathrm{nm} 23$ forms (as indicated under the graph). Staining was carried out 4 days after transfection. Data are mean values ( \pm standard deviation) of three experiments. (C) Immunoblotting assays showing expression of HA-tagged DR-nm23 and N-myc proteins in N1E 115 transfected with the empty vector or wild-type or mutant DR-nm23. (D) Densitometric analysis of the N-myc immunoblot blot in C. Data were obtained after normalization for the $\beta$-actin content 


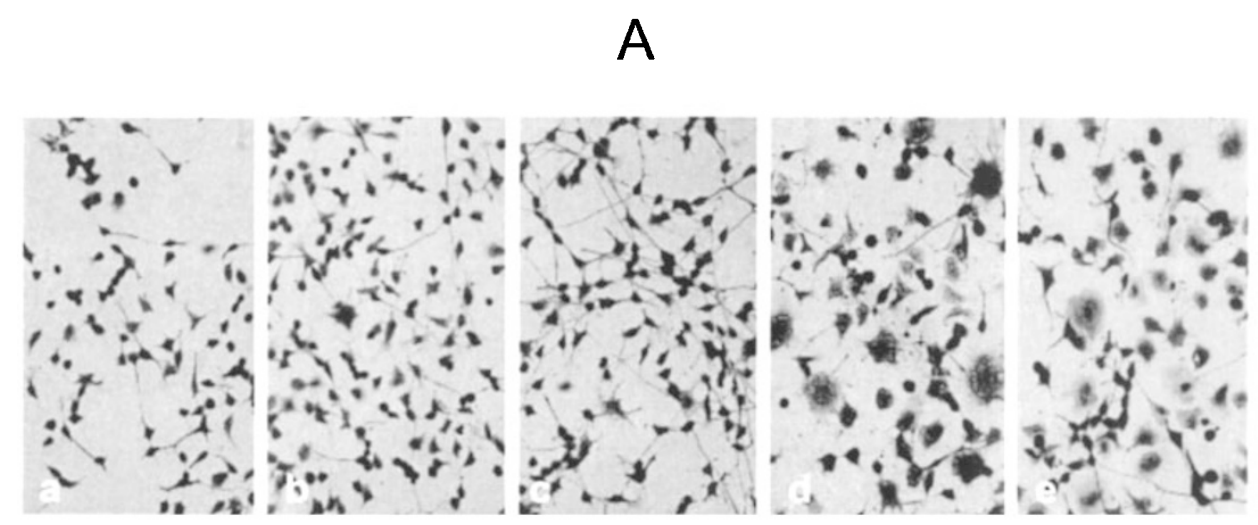

B
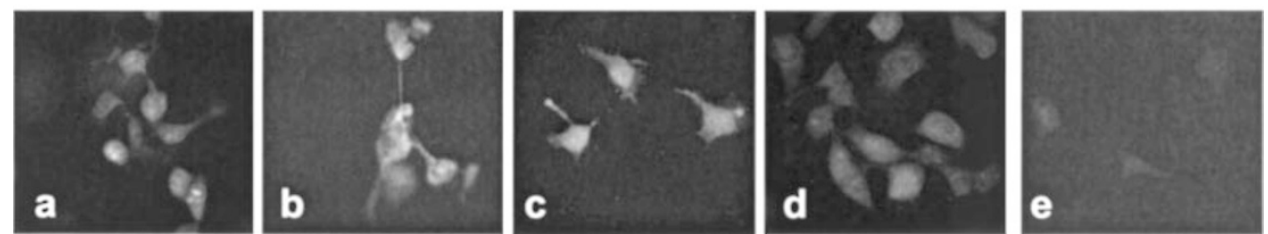

Figure 2 (A) Cell morphology of parental line transfected with the empty vector (a), DR-nm23 wild-type (b), RGD- (c), S-P (d) and H-Q (e) mutants grown in $0.1 \%$ FBS for $48 \mathrm{~h}$. (B) Neurofilament $160 \mathrm{kDa}$ detection by indirect immunofluorescence of parental line transfected with the empty vector (a), DR-nm23 wild-type (b), RGD- (c), S-P (d) and H-Q (e) mutants grown in $0.1 \%$ FBS for $48 \mathrm{~h}$

protein, subcellular fractions were prepared and tested for DR-nm23 expression. The wild-type and mutant DR-nm23 forms were always detected in the heavy membrane (HM) and cytoplasmic (C) fractions (Figure 4). Unlike the wild-type and the H-Q mutant, we could not detect DR-nm23 S-P and RGDmutants in the light membrane (LM) fraction. It should also be noted that the $\mathrm{H}-\mathrm{Q}$ mutant seems more abundant in the $\mathrm{LM}$ than in the HM fraction (Figure 4).

\section{DR-nm23 binds Nm23-H1 and Nm23-H2 proteins}

To be catalytically active as nucleoside diphosphate kinases (NDPK), ${ }^{20} \mathrm{Nm} 23-\mathrm{H} 1$ and $\mathrm{Nm} 23-\mathrm{H} 2$ proteins associate in vivo as homo-hexamers. Heterohexamers of catalitically active nm23, which allows the formation of various isoenzymes, have also been demonstrated in vitro. ${ }^{20}$ Furthermore, Nm23$\mathrm{H} 1$ has recently shown to form in vitro a complex with GAPDH. ${ }^{16}$ To test the ability of DR-nm23 to form complexes with other proteins in vivo, cell lysates obtained after metabolic labeling of the wild-type- and mutant-transfected cells were immunoprecipitated with an anti-HA antibody. The immunoprecipitated proteins were separated by SDS-PAGE and autoradiographed.

A band of about $19 \mathrm{kDa}$ corresponding to a protein with a size comparable to that of $\mathrm{Nm} 23$ proteins was detected only in the wild-type immunoprecipitate (Figure 5A upper panel). Thus, the anti-HA immunoprecipitates from cell lysates of wild-type and mutant DR-nm23 transfectants were separated by SDS-PAGE and blotted with an antibody recognizing both $\mathrm{nm} 23-\mathrm{H} 1$ and $\mathrm{nm} 23-\mathrm{H} 2$. A band

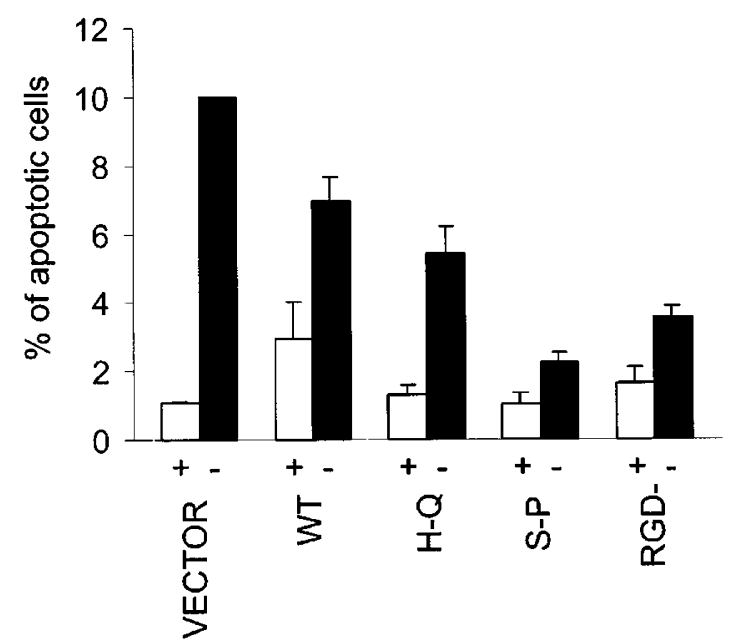

Figure 3 Effects of DR-nm23 on apoptosis: Percentage of apoptotic cells in transfected cells grown in basal conditions $(+)$, and in serum deprivation for $48 \mathrm{~h}(-)$, detected by TUNEL assay. Data are mean values $( \pm$ standard deviation) of four experiments

of $19 \mathrm{kDa}$ was detected only in the cell lysate of wild-type transfectants, indicating that DR-nm23 forms complexes with the other two members of the family (Figure 5A, lower panel). The three mutants used in this study lacked the ability to form hetero-multimers with other proteins of the same gene family, possibly because of modifications in 


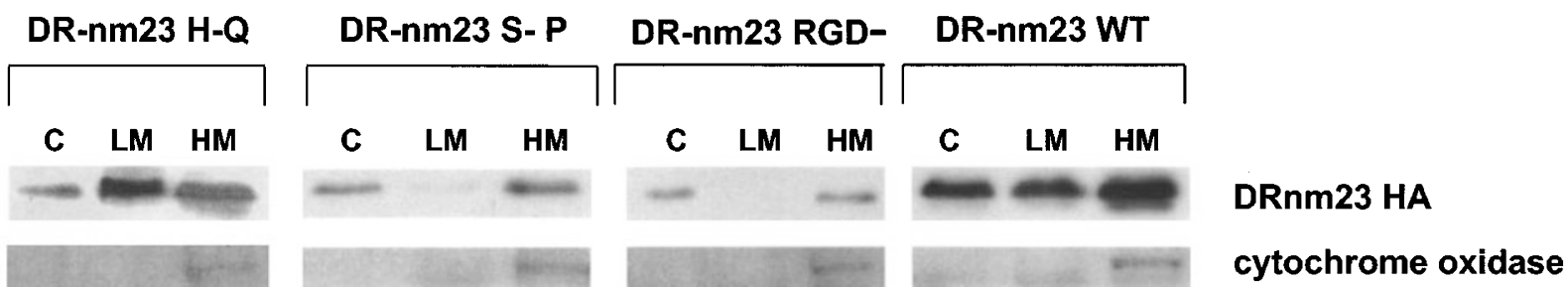

Figure 4 Sub-cellular localization of wild-type and mutant DR-nm23. Cell lysates from transfected cells were separated in heavy membrane (HM), cytosolic (C) and light membrane (LM) fractions and analyzed by SDS-PAGE/immunoblotting assay with an anti HA antibody. An antibody anti-cytochrome oxidase was used as a control for the presence of mitochondria in the HM fractions

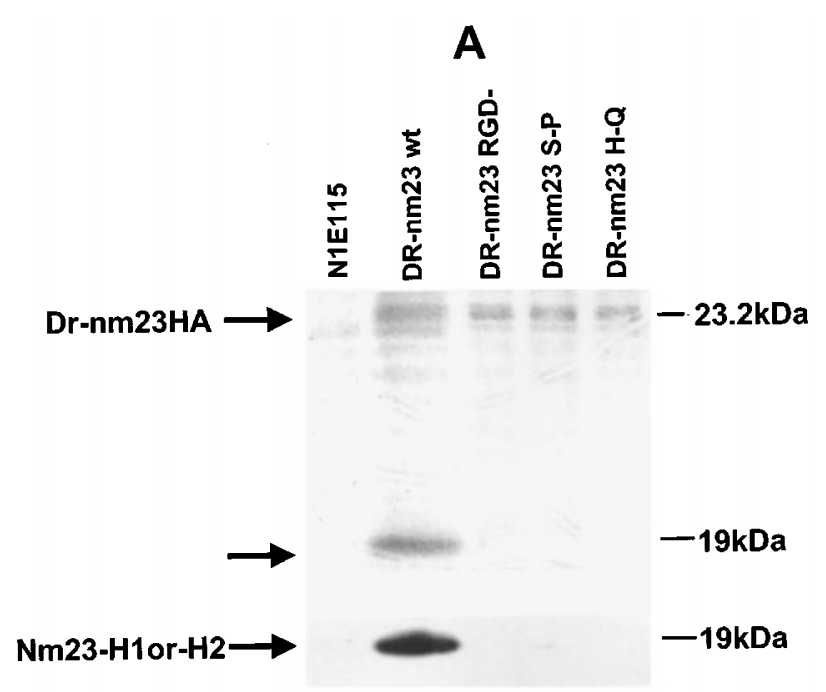

B

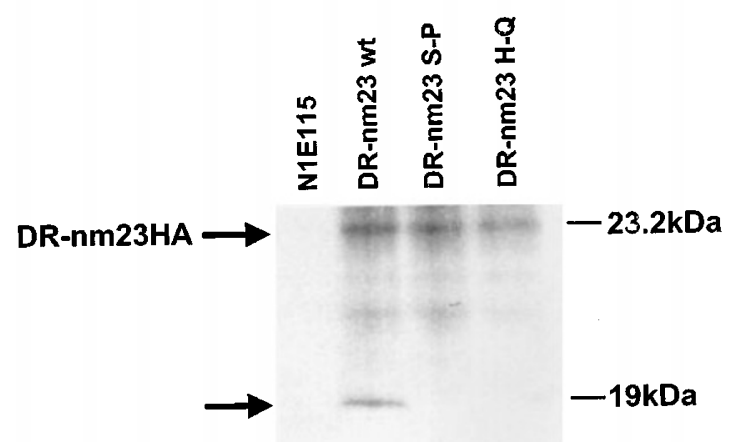

Figure 5 Co-immunoprecipitation of DR-nm23 with nm23-H1 and nm23-H2. (A) upper panel: Immunoprecipitation with an anti-HA antibody in lysates of transfected cells, after metabolic labeling with ${ }^{35} \mathrm{~S}$-methionine and -cysteine. A specific band of $19 \mathrm{kDa}$ was detected only in the wild-type lane. Lower panel: Immunoprecipitation experiment as in A followed by immunoblotting with an anti nm23-H1/H2 antibody. Co-immunoprecipitation of DR-nm23 and nm23-H1 and $\mathrm{H} 2$ was detected only in the wild-type DR-nm23. (B) Immunoprecipitation with an anti-HA antibody in lysates of transfected cells, after metabolic labeling with ${ }^{32} \mathrm{P}$-orthophosphoric acid

protein conformation masking regions necessary for the binding. These experiments do not rule out the possibility that either wild-type DR-nm23 or the mutants can form homohexamers, since the anti-nm23 antibody that we used does not cross-react with DR-nm23.

To test if DR-nm23 is present in a phosphorylated form in transfected cells and whether there were differences between WT and mutant DR-nm23, immunoprecipitation with the anti HA antibody was performed after labeling transfected cells with [ ${ }^{32} \mathrm{P}$ ]orthophosphate. Phosphorylation of WT and mutant DR-nm23 was essentially identical (Figure 5B). Interestingly a band of approximately $19 \mathrm{KDa}$, similar to that seen in the ${ }^{35} \mathrm{~S}$-labeled immunoprecipitates, was also detected in wild-type transfected cells, suggesting that phosphorylated nm23-H1 or $\mathrm{H}_{2}$ interacts with phosphorylated DR-nm23.

\section{Discussion}

The relationship between differentiation and expression of nm23 family genes is still controversial. The prototype member nm23- $\mathrm{H} 1$ has been alternatively described as a differentiation inhibitor ${ }^{21}$ or inducer $^{22}$ depending on the cellular context in which its biological function has been tested. In neuroectodermal PC12 cells, nm23-H1 expression is positively correlated with cell differentiation. ${ }^{22}$

In a recent report, ${ }^{5}$ we have shown that overexpression of DR-nm23 promotes differentiation of neuroblastoma cells towards neuronal and schwannocitic phenotypes, and induces changes in the adhesion properties of the cells due to a modulation in the pattern of integrin expression. We show here that the integrity of NDP kinase function and the phosphorylation of serine 61 are essential for differentiation induction of neuroblastoma cells. In fact, both the $H-Q$ mutant, which has a mutation compromising the enzymatic activity, and the S-P mutant, in which a site of phosphorylation at a serine 61 , homologous to serine 44 in $\mathrm{Nm} 23-\mathrm{H} 1,{ }^{17}$ has been removed, were unable to induce morphological and/or biochemical changes characteristic of differentiation. MacDonald et al. ${ }^{17}$ suggested that NDPK activity of nm23$\mathrm{H} 1$ is necessary but not sufficient for inducing metastatic suppression and must be complemented by phosphorylation of serine 44. Our data suggest that also in DR-nm23 the H-Q and S-P mutations are somehow linked causing similar phenotypic effects. In addition, the two mutants, H-Q and S$P$, not only lost the ability to induce differentiation but, rendered the cells more resistant to differentiation induced by decreasing serum concentration. Thus, the disruption of the NDP kinase activity and the mutation in the phosphor- 
ylation site at serine 61 seem to have an inhibitory effect on the differentiation-inducing activity of DR-nm23 in neuroblastoma cells. NDPK enzymatic activity seems to be involved in the regulation of microtubules polymerization and stability, the movement along microtubules, and in nucleotide channeling processes. ${ }^{23}$ Accordingly, NDP kinases are frequently associated with modulation of important processes such as normal development, ${ }^{10}$ proliferation, ${ }^{11}$ tumor progression ${ }^{24}$ and differentiation. ${ }^{12} \mathrm{~A}$ direct involvement of DR-nm23 as a NDP kinase in neuroblastoma differentiation could explain the results obtained with the $\mathrm{H}-\mathrm{Q}$ mutant. On the other hand, phosphorylation of serine 61 , which is lacking in the S-P mutant, could be part of a phosphorylation/dephosphorylation pathway equally essential for signal transduction.

Noteworthy, in 32Dcl3 cells deprived of IL-3 and treated with G-CSF, overexpression of DR-nm23 is incompatible with terminal differentiation and triggers massive apoptosis. ${ }^{4}$ In neuroblastoma cells, over-expression of DR-nm23 does not lead to increased apoptosis. On the contrary, expression of both the wild-type and the mutant forms of DR-nm23 protects neuroblastoma cells from apoptosisinduced by serum deprivation. Together, the findings in the hematopoietic model and our data in neuroblastoma cells suggest that the effects of DR-nm23 expression either on differentiation or apoptosis are strictly dependent on the cellular context.

The DR-nm23 mutant lacking the RGD domain retained the ability to induce phenotypic modifications (neurites elongation and decrease of $\mathrm{N}$-myc oncogene expression) typically associated with induction of differentiation. Thus, the RGD domain, which has been indicated as a possible site for interaction with other proteins, is not necessary to trigger differentiation. Nevertheless, it should be stressed that binding through the RGD has never been demonstrated for DR-nm23 suggesting that the RGD residues of DR-nm23 structure must not be accessible for interactions with other ligands.

In this study, we show that DR-nm23 localizes in the extranuclear compartment ${ }^{5}$ (Figure 4) with a prevalence, similarly to $\mathrm{nm} 23-\mathrm{H} 4{ }^{6}{ }^{6}$ in the $\mathrm{HM}$ fraction where mitochondria reside. Lesser amounts were detectable also in the LM and $C$ fractions. Notably, the presence of DR-nm23 in the LM fraction is abolished by the S-P and RGD-mutations. this could be due to conformational changes which may impair the docking to the light membranes, possibly by abolishing interaction(s) with light membrane-specific proteins.

Our immunoprecipitation experiments demonstrate for the first time that DR-nm23 protein forms complexes in vivo with another member of the family, $\mathrm{nm} 23-\mathrm{H} 1$ or $\mathrm{nm} 23-\mathrm{H} 2$. The formation of heteropolymers does not seem necessary for differentiation induction, because the mutant RGD-, which does not dimerize with $\mathrm{nm} 23-\mathrm{H} 1$ and $\mathrm{H} 2$, is still able to induce differentiation. However, our data do not rule out the possibility that the RGD mutant forms homopolymers which we could not detect since the antibody used in the immunoprecipitation experiments did not cross-react with DR-nm23. Further evidence that the ability to form heteropolymers is uncoupled from the differentiative effect of DR-nm23 stems from the observation that also the differentiation-incompetent $\mathrm{S}-\mathrm{P}$ and $\mathrm{H}-\mathrm{Q}$ mutants are unable to form heteropolymers.

The mutant S-P lacks serine 61 which is likely to be a phosphorylation site of DR-nm23 similarly to serine 44 in $\mathrm{nm} 23-\mathrm{H} 1$. The immunoprecipitation experiment carried out with ${ }^{32} \mathrm{P}$-orthophosphate labeled cells did not show differences in the level of phosphorylated WT and mutant DR-nm23. Conceivably, a relatively high number of potential phosphorylation sites in DR-nm23 may mask the absence of one of them in the S-P mutant.

In the same experiment a band of $19 \mathrm{Kda}$, similar to that detected in the immunoprecipitation with ${ }^{35} \mathrm{~S}$-labeled cells, is visible only with the WT DR-nm23. This suggests that although physical contact between DR-nm23 and nm23-H1 or $\mathrm{H} 2$ occurs with both proteins in a phosphorylated form, phosphorylation alone is not a sufficient requirement since the phosphorylated S-P and $\mathrm{H}-\mathrm{Q}$ forms are unable to coimmunoprecipitate other members of the nm23 family.

In summary, our data shed light on some of the essential requirements (i.e. NDPK activity and phosphorylation in serine 61) for the differentiative effect of DR-nm23 on neuroectodermal cells. This is particularly interesting in neuroblastoma where induction of differentiation, blocked in the tumor cells, could provide an interesting therapeutic strategy.

\section{Materials and Methods}

\section{DR-nm23 plasmids}

HA-DR-nm23 plasmids were generated as follows:

LXSP-HA wild-type DR-nm23 The HA-tagged wild-type DR-nm23 was released from the SK plasmid ${ }^{4}$ as a BamHl-Apal fragment, blunt-ended by Klenow, and cloned in the Hpal-linearized LXSP retroviral vector.

LXSP-HA S61P DR-nm23 This mutant was generated by PCR amplification from SK-HA DR-nm23 using a $5^{\prime}$ DR primer containing the BamHI site (5' ATGGATCCCGCTCCCGCACC $3^{\prime}$ ) and $3^{\prime}$ MUT DR-nm23 primer (5' CTCCTCGGAGGGCTACACCAGCTTCAG 3', in which the underlined proline triplet replaces Ser 61). Following BamHI-Eco57 restriction enzyme digestion, the resulting $210 \mathrm{bp}$ fragment was ligated together with the 470 bp Eco57-Apal fragment into the BamHI/Apal-digested SK-HA DR-nm23. The released BamHI-Apal fragment was then blunt-ended with Klenow and cloned into the Hpal-linearized LXSP vector.

LXSP-HA H134Q DR-nm23 This mutant was generated by PCR amplification from SK-HA DR-nm23 using the following primers: $5^{\prime}$ DR containing the BamHI site (5' ATGGATCCCGCTCCCGCACC 3'), 3' DR (5' CAGGTTCTTGCCAACCTCGA 3'), 5' DR (5' ATTCAGGGCAGCGACTCGGT $3^{\prime}$, in which the underlined glutamine triplet replaces Hys134), 3' DR (5' ATGGGCCCCCCCTCGACTGC 3', containing the Apal restriction site).

After restriction digestion with $B a m \mathrm{HI}$ and Apal, the PCR products (420 and $260 \mathrm{bp}$, respectively) were phosphorylated and cloned into the BamHI/Apal-digested SK-HA DR-nm23. The released BamHI-Apal fragment was then blunt-ended with Klenow and cloned in the Hpaldigested LXSP vector.

LXSP-HADRGD DR-nm23 This mutant was generated by PCR amplification from SK-HA DR-nm23 using the following primers: $5^{\prime}$ 
DR containing the BamHI site (5' ATGGATCCCGCTCCCGCACC 3'), 3' DR (5' GATGGTGCCGGGCGGGGCGT $\left.3^{\prime}\right), 5^{\prime}$ RGD- $\left(5^{\prime}\right.$ TTCTGCATCGAGGTTGGCAA 3'), 3' DR (5' ATGGGCCCCCCCTCGACTGG $3^{\prime}$, containing the Apal restriction site). After restriction digestion with BamHI and Apal, the PCR products (385 and $295 \mathrm{bp}$ respectively) were phosphorylated and cloned into the BamHI/Apaldigested SK-HA DR-nm23. The released BamHI/Apal fragment was blunt-ended with Klenow and cloned into the Apal-digested LXSP vector

pHis-WT, pHis-H134Q and pHis-S61P DR-nm23 were generated as follows (i) WT and mutant DR-nm23 were amplified from the pLXSP DR-nm23 using a 5'- upstream primer (5'-TAAGCTTTTACCGGCGCACACGAA-3') corresponding to nucleotides. 51-65 and a $3^{\prime}$-downstream primer (5'-AAAGCTTCTACTCATACAGCCAGTG-3') corresponding to nucleotides 489-506; (ii) The fragments were subcloned into pCR II TOPO (Stratagene), Hindllldigested and inserted into the Hindll site of the prokaryotic expression vector pQE-60 (Qiagen) previously mutagenized to remove the TAA stop codon preceding the Hindlll site. For functional assays, bacterially synthesized $6 \times \mathrm{His}-\left(\mathrm{NH}_{2}\right)$ tagged DRnm23 fusion proteins were purified under denaturing conditions by nickel-chromatography (Ni-NTA; Qiagen) according to the manufacturer's protocol, and renatured in $50 \mathrm{mM}$ phosphate buffer.

NDP kinase activity assay NDP kinase activity was determined as previously described. ${ }^{9}$

\section{Cell line and transfections}

The murine neuroblastoma cell line $\mathrm{N} 1 \mathrm{E} 115^{18}$ was grown in Dulbecco's modified minimal essential medium (DMEM) supplemented with $7.5 \%$ fetal bovine serum (FBS). Stable transfections with LXSP-DR-nm23 plasmids were carried out by calcium phosphate precipitation, according to standard procedures. ${ }^{25}$ Cells were selected in the presence of $2 \mu \mathrm{g} / \mathrm{ml}$ puromycin for 21 days. Pools of transfectants (20-30 single clones) were collected and expanded.

\section{B-galactosidase assay}

N1E115 cells were co-transfected with LXSP-DR-nm23 (wild-type and mutants) and $\beta$-galactosidase plasmid (CMV- $\beta$-Gal) in a ratio $5: 1$. After 4 days cells were fixed in paraformaldheyde and glutaraldheyde and stained with a solution containing $1 \mathrm{mg} / \mathrm{ml} \mathrm{X-gal,} 2 \mathrm{mM} \mathrm{MgCl}$, $4 \mathrm{mM}$ potassium ferricyanide and $4 \mathrm{mM}$ potassium ferrocyanide. Stained cells were counted and morphologically scored for differentiation. ${ }^{25}$

\section{Indirect immunofluorescence}

Cells were fixed in $3.4 \%$ paraformaldheyde in PBS and permeabilized in $0.25 \%$ Triton X-100. Immunofluorescence staining was carried out using the monoclonal anti-neurofilament 160 NN18 (SIGMAALDRICH) diluted $1: 40$ as primary antibody and the goat anti-mouse IgG (Fc specific) FITC conjugate (SIGMA-ALDRICH) diluted 1:125.

\section{Western blot analysis}

Parental and DR-nm23-transfected N1E115 cells $\left(5 \times 10^{5}\right)$ were lysed in $20 \mu l 50 \mathrm{mM}$ Tris-HCl (pH 7.4), $250 \mathrm{mM} \mathrm{NaCl}, 5 \mathrm{mM}$ EDTA, $50 \mathrm{mM}$ sodium fluoride, $0.1 \mathrm{mM}$ sodium vanadate, $0.1 \%$ Triton- $\mathrm{X} 100,1 \mathrm{mM}$ phenyl methyl sulphonyl fluoride (PMSF) and $10 \mu \mathrm{g} / \mathrm{ml}$ leupeptin. Equal amounts of proteins were separated by SDS-PAGE and transferred to a PVDF membrane (Amersham) as previously described. ${ }^{26}$ Specific signals were detected by ECL chemiluminescence reaction kit according to the manufacturer's instructions (Amersham). Wild-type and mutant DR-nm23 tagged with the HA epitope were detected using a anti-HA monoclonal antibody (Boehringer), $\mathrm{N}$-myc oncogene expression was evaluated using a anti-N-myc monoclonal antibody (Ab-1, Santa Cruz Biotechnology), $\beta$ actin was detected with an anti- $\beta$ actin monoclonal antibody (Sigma).

\section{Immunoprecipitations}

N1E115 and transfected cell lines were metabolically labeled with a mix of ${ }^{35} \mathrm{~S}$-methionine and -cystein $(0.15 \mathrm{mCi} / \mathrm{ml})$ or with ${ }^{32} \mathrm{P}$. orthophosphoric acid $(0.25 \mathrm{mCi} / \mathrm{ml})$ for $3 \mathrm{~h}$. Extracts were prepared in $50 \mathrm{mM}$ Tris- $\mathrm{HCl}$ (pH 8.0), $120 \mathrm{mM} \mathrm{NaCl}, 5 \mathrm{mM}$ EDTA, $0.5 \%$ Nonidet $\mathrm{P}-40,10 \mu \mathrm{M}$ Na-orthovanadate, $1 \mathrm{mM} \mathrm{PMSF}$, and $5 \mu \mathrm{g} / \mathrm{ml}$ leupeptin in the case of ${ }^{35} \mathrm{~S}$-labeling or in $50 \mathrm{mM}$ Tris- $\mathrm{HCl}(\mathrm{pH} 8.0), 20 \mathrm{mM} \mathrm{NaCl}$ $100 \mathrm{mM} \mathrm{NaF}, 30 \mathrm{mM}$ Na-pyrophosphate, $3 \mathrm{mM}$ Na-orthovanadate, $10 \mathrm{mM}$ EDTA, $1 \%$ Nonidet P-40,1 mM PMSF, $1 \mathrm{mg} / \mathrm{ml}$ aprotinin, $1 \mathrm{mg} /$ $\mathrm{ml}$ leupeptin, $0.02 \% \mathrm{NaN}_{3}$ in the case of ${ }^{32} \mathrm{P}$ labeling. Immunoprecipitations were carried out essentially as described ${ }^{27}$ using an anti$\mathrm{HA}$ antibody. Immunoprecipitated proteins were run on a $12 \%$ SDSPAGE, dried and exposed with an X-ray film.

Immunoprecipitations were performed also without metabolic labeling and followed by Western blot analysis using a anti-nm23 H1 polyclonal antibody (C-20) (Santa Cruz Biotechnology). Detection was carried out with ECL chemiluminescence reaction kit (Amersham).

\section{Preparation of subcellular fractions}

$10^{7}$ LXSP-DR-nm23 wild-type and mutant transfected cells were resuspended in hypotonic buffer containing $0.2 \mathrm{mM}$ PMSF, $5 \mu \mathrm{g} / \mathrm{ml}$ leupeptin, $5 \mu \mathrm{g} / \mathrm{ml}$ aprotinin, $0.7 \mu \mathrm{g} / \mathrm{ml}$ pepstatin A, lysed in a Dounce homogenizer and centrifuged at $500 \times \mathrm{g}$ for $5 \mathrm{~min}$ at $4^{\circ} \mathrm{C}$ to discard nuclei. Supernatants were centrifuged at $10000 \times \mathrm{g}$ for $30 \mathrm{~min}$ at $4^{\circ} \mathrm{C}$ to obtain the heavy membranes (HM) fraction as a pellet. Supernatants were then centrifuged for $1 \mathrm{~h}$ and $30 \mathrm{~min}$ at $150000 \times \mathrm{g}$ to obtain the light membrane (LM) as a pellet and the supernatant cytosolic (C) fractions. The HM and LM were resuspended in a Triton X-100 lysis buffer. $^{28}$

\section{Apoptosis}

To determine the presence of apoptotic cells, transfectant and control cells were grown in DMEM supplemented with $0.5 \%$ FBS. After $48 \mathrm{~h}$ apoptotic cells were scored TUNEL assay using a kit according to the manufacturer's instructions (Boehringer Mannheim).

\section{Acknowledgements}

This work was supported by grants of the Associazione Italiana per la Ricerca sul Cancro (AIRC) and of the Associazione Italiana per la Lotta al Neuroblastoma (to $G$ Raschellà). Barbara Tanno is supported by a fellowship from the Fondazione Italiana per la Ricerca sul Cancro (FIRC).

\section{References}

1. Bevilacqua G, Sobel ME, Liotta LA and Steeg PS (1989) Association of low nm23 RNA levels in human primary infiltrating ductal breast carcinomas with lymph node involvement and other histopathological indicators of high metastatic potential. Cancer Res. 49: 5185-5190 
2. Steeg PS, Bevilacqua G, KopperI, Thorgeirsson UP, Talmadge JE, Liotta LA and Sobel ME (1998) Evidence for a novel gene associated with a low metastatic potential. J. Natl. Cancer Inst. 80: 200-204

3. Leone A, Flatow U, King CR, Sandeen MA, Margulies IMK, Liotta LA and Steeg PS (1991) Reduced tumor incidence, metastatic potential, and cytokine responsiveness of nm23-transfected melanoma cells. Cell 65: 25-35

4. Venturelli D, MartinezR, Melotti P, Casellal, Peschle C, Cucco C, Spampinato G, Darzynkiewicz Z and Calbretta B (1995) Overexpression of DR-nm23, a protein encoded by a member of the nm23 gene family, inhibits granulocyte differentiation and induces apoptosis in 32Dc13 myeloid cells. Proc. Natl. Acad. Sci. USA 92: 7435-7439

5. Amendola R, Martinez R, Negroni A, Venturelli D, Tanno B, Calabretta B and Raschellà G (1997) DR-nm23 gene expression in neuroblastoma cells: relationship to integrin expression, adhesion characteristics, and differentiation. J. Natl. Cancer Inst. 89: 1300-1310

6. Milon L, Rousseau-Merck M, Munier A, Erent M, Lascu I, Capeau J and Lacombe M (1997) Nm23-H4, a new member of the human nm23/nucleoside diphosphate kinase gene family localized on chromosome 16q13. Hum. Genet. 99: 550-557

7. Munier A, Feral C, Milon L, Phung-Ba Pinon V, Gyapay G, Capeau J, Guellaen G and Lacombe M-L (1998) A new human nm23 homologue (nm23-H5) specifically expressed in testis germinal cells. FEBS Lett. 434: 289-294

8. Daberna S, Larou M, Masse K, Hokfelt T, Mayer G, Daniel JY and Landry M (1999) Cloning of a second nm23-M1 cDNA: expression in the central nervous system of adult mouse and comparison with nm23-M2 distribution. Brain Res. Mol. Brain Res. 63: 351-365

9. Gonin P, Xu Y, Milon L, Dabernat S, Morr M, Kumar R, Lacombe M-L, Janin J and Lascu I (1999) Catalytic mechanism of nucleoside diphosphate kinase investigated using nucleotide analogues, viscosity effects, and X-ray crystallography. Biochemistry 38: 7265-7272

10. Biggs J, Hersperger E, Steeg PS, Liotta LA and Shearn A (1990) A drosophila gene that is homologous to a mammalian gene associated with tumor metastasis codes for a nucleoside diphosphate kinase. Cell 63: 933-940

11. Keim D, HailatN, Melhem R, ZhuXX, LascuI, Veron M, StralherJand Hanash SM (1992) Proliferation-related expression of $\mathrm{p} 19 / \mathrm{nm} 23$ nucleoside diphosphate kinase. J. Clin. Invest. 89: 919-924

12. Willems R, Van Bockstaele DR, Lardon F, Lenjou M, Nijs G, Snoeck HW, BernemanZNand Slegers $H$ (1998) Decrease in nucleotide disphosphate kinase (NDPK/nm23) expression during hematopoietic maturation. J. Biol. Chem. 273: $13663-13668$

13. MacDonald NJ, Freije JMP, Stracke ML, Manrow RE, MA and Steeg PS (1996) Site-directed mutagenesis of nm23-H1. J. Biol. Chem. 271: 25107-25116

14. Postel EH, Berberich SJ, Flint SJ and Ferrone CA (1993) Human c-myc transcription factor PuF indentified as nm23-H2 nucleotide diphosphate kinase, a candidate suppressor of tumor metastasis. Science 261: 478-480

15. Postel EH, Weiss WH, Beneken J and Kirtane A (1996) Mutational analysis of NM23-H2/NDP kinase identifies the structural domains critical to recognition of a c-myc regulatory element. Proc. Natl. Acad. Sci. USA 93: 6892-6897
16. EngelM, Seifert M, TheisingerB, SeyfertU and Welter C (1998) Glyceraldehyde3-phosphate dehydrogenase and nm23-H1/nucleoside diphosphate kinase A.J. Biol. Chem. 273: 20058-20065

17. MacDonald NJ, De La Rosa A, Benedict MA, Freije JMP, Krutsch H and Steeg $P$ (1993) A serine phosphorylation of $n m 23$, and not its nucleoside diphosphate kinase activity, correlates with suppression of tumor metastatic potential. J. Biol. Chem. 268: 25780-25789

18. Kimhi Y, Palfrey C, Spector I, Barak Y and Littauer UZ (1976) Maturation of neuroblastoma cells in the presence of dimethysulphoxide. Proc. Natl. Acad. Sci. USA 73: $462-466$

19. Thiele CJ, Reynolds CP and Israel M (1985) Decreased expression of N-myc precedes retinoic acid-induced morphological differentiation of human neuroblastoma. Nature 313: 404-406

20. Gilles AM, Presecan E, Vonica A and Lascu I (1991) Nucleoside diphosphate kinase from human erythrocytes. Structural characterization of the two polypeptide chains responsible for heterogeneity of the hexameric enzyme. J. Biol. Chem. 266: 8784-8789

21. Yokoyama A, Okabe-Kado J, Sakashita A, Maseki N, Kaneko Y, Hino K, Tomoyasu S, Tsuruoka N, Kasukabe T and Honma Y (1996) Differentiation inhibitory factor nm23 as a new prognostic factor in acute monocytic leukemia. Blood 88: 3555-3561

22. Gervasi F, D'Agnano I, Vossio F, Zupi G, Sacchi A and Lombardi D (1996) Nm23 influences proliferation and differentiation of $\mathrm{PC} 12$ cells in response to nerve growth factor. Cell Growth Differ. 7: 1689-1695

23. Reddy GPV and Pardee AB (1980) Multienzyme complex for metabolic channeling in mammalian DNA replication. Proc. Natl. Acad. Sci. USA 77:33123316

24. De La Rosa A, Williams R and Steeg PS (1995) Nm23/nucleoside diphosphate kinase: Toward a structural and biochemical understanding of its biological functions. BioEssay 17: 53-62

25. Raschellà G, Tanno B, Bonetto F, Negroni A, Claudio PP, Baldi A, Amendola R, Calabretta B, Giordano A and Paggi MG (1998) The RB-related gene Rb2/p130 in neuroblastoma differentiation and in B-myb promoter down-regulation. Cell Death Differ. 5: 401-407

26. Baldi A, De Luca A, Claudio PP, Giordano GG, Tommasino M, Paggi MG and Giordano A (1995) The RB2/p130 gene product is a nuclear protein whose phosphorylation is cell cycle regulated. J. Cell Biochem. 59: 402-408

27. Wenzel A, Cziebluch C, Hamann U, Schurmann J and Schwab M (1991) The Nmyc oncoprotein is associated in vivo with thr phosphoprotein Max (p20/22) in human neuroblastoma cells. EMBO J. 10: 3703-3712

28. Wang GW, Rapp URand ReedJC (1996) Bcl-2 targets the protein kinase Raf- 1 to mitochondria. Cell 87: 629-638 